\title{
Etude sur la préparation de ferments lactiques très actifs
}

\author{
par \\ T. SOZZI \\ Travaux effectués dans le Département Recherche et Développement \\ de la Société d'Assistance Technique pour produits Nestlé S.A. \\ Lausanne (Suisse)
}

(avec la collaboration technique de Mlle R. ASTRUC)

L'amélioration des procédés de fabrication des fromages traditionnels et la mise au point de nouvelles technologies sont restées jusqu'à ce jour sous la dépendance de la vitesse de développement des cultures lactiques.

Différents auteurs ont proposé des méthodes permettant de produire une masse importante de cellules, comme la culture en milieu à $\mathrm{pH}$ constant [1], ou l'utilisation de suspensions concentrées et congelées de bactéries cultivées en milieu synthétique [10].

Dernièrement Bristol et Martin [3] ont montré que des levains, préparés dans du lait et utilisés en pleine phase exponentielle de croissance, avant la coagulation, étaient supérieurs aux levains traditionnels pour la production de Cheddar.

Bottazzi [2] et Sozzi [9] ont également noté que les cultures naturelles destinées à la fabrication des fromages italiens à pâte molle sont employées juste avant la coagulation du milieu lactique.

Certes plusieurs travaux [4] ont été faits sur l'acidification directe du lait avec différents acides organiques sans recourir à des cultures. Mais les produits obtenus n'ont pas les caractéristiques organoleptiques désirées.

Le but de la présente étude était de mettre au point une méthode très simple de préparation de ferments lactiques à grande activité, destinés à être utilisés dans les processus de fermentation biologique des produits laitiers et dans les fromageries.

\section{Souches}

\section{MATERIELS ET METHODES}

L'étude a porté sur 15 souches lactiques bien connues de nous quant à leur comportement général. 
Streptococcus lactis : C6, C10 (reçus du professeur V. Bottazzi, Université catholique de Piacenza), Ca4 et 272 (isolés par nous).

Streptococcus diacetylactis : SDW (isolé par nous), 222 (reçu du professeur B. Habaj, Institut de l'Industrie laitière, Laboratoire de cultures pures, Olsztyn Kor Towo - Pologne).

Streptococcus cremoris : TR et RI (reçu du docteur J. H. Galloway, Dept. of Dairy technology, the West Scotland Agricultural College).

Streptococcus thermophilus : A.T.C.C. $\mathrm{n}^{\circ}$ 19987, L 12,24 et S 19 (isolés par nous).

Lactobacillus lactis : A.T.C.C. $\mathrm{n}^{\circ}$ 15807, A (isolé par nous).

Lactobacillus helveticus : H2 (reçu du professeur V. Bottazzi, Université catholique de Piacenza).

\section{Entretien des souches}

Les souches sont repiquées deux fois par semaine, à raison de 1 p. 100 , dans $10 \mathrm{ml}$ de lait, reconstitué à 10 p. 100 à partir de lait écrémé en poudre additionné de 1 p. 1000 d'extrait de levure (Difco) et stérilisé à $115^{\circ} \mathrm{C}$ pendant $35 \mathrm{mn}$.

L'incubation s'effectue à $30^{\circ} \mathrm{C}$ pour les souches mésophiles (Str. lactis, Str. diacetylactis, Str. cremoris), à $40^{\circ} \mathrm{C}$ pour les souches thermophiles (Str. thermophilus, L. lactis, L. helveticus).

Les tubes sont refroidis dans un courant d'eau froide dès la coagulation des cultures et conservés dans l'armoire frigorifique $\left(+4^{\circ} \mathrm{C}\right)$.

\section{Préparation des échantillons}

Pour déterminer l'activité des souches en fonction de la durée de l'incubation, on incube en même temps une série de 6 biberons de $200 \mathrm{ml}$ de lait stérile (préparé comme ci-dessus) inoculés avec $2 \mathrm{ml}$ d'une culture de laboratoire âgée de $24 \mathrm{~h}$.

Le premier échantillon est sorti du bain-marie environ $1 \mathrm{~h}$ avant la coagulation de la culture, soit après $2 \mathrm{~h}$ d'incubation pour les Str. thermophilus, après $5 \mathrm{~h}$ pour les Str. lactis, L. lactis et L. helveticus, après $6 \mathrm{~h}$ pour les Str. diacetylactis et Str. cremoris.

Le deuxième biberon est analysé dès la coagulation de la culture, le troisième après $8 \mathrm{~h}$ d'incubation, le quatrième après $12 \mathrm{~h}$, le cinquième après $18 \mathrm{~h}$ et le dernier après $24 \mathrm{~h}$.

Chaque échantillon est soumis aux analyses suivantes :

\section{Analyse des échantillons}

1) Acidité et $\mathrm{pH}$ : Méthode Soxhlet-Henkel

On pèse $20 \mathrm{~g}$ de lait acidifié et on titre avec de l'hydroxide de sodium N/4 jusqu'à : $\mathrm{pH}=8.4$. 
On multiplie le nombre de $\mathrm{ml}$ de $\mathrm{NaOH}$ employés par 5 pour obtenir l'acidité de la culture en ${ }^{\circ} \mathrm{SH}$.

2) Dénombrement des germes

On effectue des dilutions décimales de la culture dans une solution de Ringer au quart, (Quarter strength Ringer solution, BDH), stérile. Dans une boîte de Pétri, on mélange $1 \mathrm{ml}$ de chacune des dilutions choisies avec $10 \mathrm{ml}$ de milieu [6] M.R.S. gélosé, fondu et ramené à $50^{\circ} \mathrm{C}$.

On effectue la numération après $72 \mathrm{~h}$ d'incubation à $30^{\circ} \mathrm{C}$ ou $40^{\circ} \mathrm{C}$ selon les souches.

\section{3) Pouvoir acidifiant}

On entend par pouvoir acidifiant la capacité d'une culture inoculée sur milieu standard (lait pasteurisé) de produire de plus ou moins grandes quantités d'acide lactique dans un intervalle de temps donné.

Mode opératoire : Du lait écrémé en poudre est reconstitué à 10 p. 100 dans de l'eau distillée sans ajouter d'extrait de levure. On répartit dans des biberons à raison de $200 \mathrm{ml}$ et on pasteurise à $95^{\circ} \mathrm{C}$ pendant $45 \mathrm{mn}$.

On refroidit à la température d'inoculation des souches et on inocule avec $2 \mathrm{ml}$ de l'échantillon à analyser. On relève le $\mathrm{pH}$ et le - $\mathrm{SH}$ du milieu avant incubation.

Après une incubation de $3 \mathrm{~h}$ pour les Str. thermophillus et de $6 \mathrm{~h}$ pour toutes les autres souches, le $\mathrm{pH}$ et l'acidité acquis par les cultures sont déterminés.

On peut alors calculer les valeurs suivantes que l'on nomme pouvoir acidifiant :

$\Delta 3$ : acidité acquise après $3 \mathrm{~h}$ d'incubation diminuée de l'acidité initiale,

$\Delta 6$ : acidité acquise après $6 \mathrm{~h}$ d'incubation diminuée de l'acidité initiale.

\section{Cultures maintenues dans un milieu à pH constant}

Trois souches ont été utilisées dans ce travail :

Str. thermophilus L 12

Str. lactis 272

L. lactis A

Les essais ont été faits dans une cuve contenant 1001 de lait stérilisé par injection de vapeur à $150^{\circ} \mathrm{C}$ pendant $2 \mathrm{sec}$. Le milieu est inoculé avec 1 p. 100 de la souche à tester.

Le $\mathrm{pH}$ est maintenu à la valeur constante de $6,5 \pm 0,1$ par addition automatique d'une solution de $\mathrm{NaOH}$ à $20 \mathrm{p}$. 100 grâce à une pompe péristaltique stérile commandée par le pHmètre. 
TABLEAU 1. - Activité des Str. lactis en fonction du temps d'incubation des cultures

\begin{tabular}{|c|c|c|c|c|c|}
\hline Souches & $\begin{array}{c}\text { Durée } \\
\text { d'incubation } \\
\text { à } 30^{\circ} \mathrm{C}\end{array}$ & $\mathrm{pH}$ & ${ }^{\circ} \mathrm{SH}$ & $\begin{array}{l}\text { Nombre de } \\
\text { germes/ml } \\
\quad \times 10^{7}\end{array}$ & $\begin{array}{c}\text { Pouvoir } \\
\text { acidifiant } \\
\Delta 6\end{array}$ \\
\hline $\mathrm{Ca} 4$ & $\begin{aligned} 5 \mathrm{~h} \\
* 5 \mathrm{~h} 30 \\
8 \mathrm{~h} \\
12 \mathrm{~h} \\
18 \mathrm{~h} \\
24 \mathrm{~h}\end{aligned}$ & $\begin{array}{l}5.1 \\
5.0 \\
4.8 \\
4.5 \\
4.4 \\
4.3\end{array}$ & $\begin{array}{l}18.4 \\
19.4 \\
26.8 \\
31.8 \\
33.7 \\
35.8\end{array}$ & $\begin{array}{l}136 \\
138 \\
175 \\
217 \\
135 \\
114\end{array}$ & $\begin{array}{l} \\
4.0 \\
5.0 \\
5.0 \\
3.5 \\
3.1 \\
1.8\end{array}$ \\
\hline 272 & $\begin{array}{c}* 5 \mathrm{~h} \\
8 \mathrm{~h} \\
12 \mathrm{~h} \\
18 \mathrm{~h} \\
24 \mathrm{~h}\end{array}$ & $\begin{array}{l}4.9 \\
4.6 \\
4.5 \\
4.4 \\
4.3\end{array}$ & $\begin{array}{l}20.2 \\
28.6 \\
32.6 \\
34.3 \\
35.5\end{array}$ & $\begin{array}{r}135 \\
113 \\
160 \\
147 \\
63\end{array}$ & $\begin{array}{l}8.6 \\
7.6 \\
5.9 \\
4.7 \\
4.2\end{array}$ \\
\hline $\mathrm{C} 6$ & $\begin{array}{r}* 5 \mathrm{~h} \\
8 \mathrm{~h} \\
12 \mathrm{~h} \\
18 \mathrm{~h} \\
24 \mathrm{~h}\end{array}$ & $\begin{array}{l}4.9 \\
4.5 \\
4.4 \\
4.35 \\
4.3\end{array}$ & $\begin{array}{l}21.3 \\
31.4 \\
35.6 \\
37.7 \\
39.1\end{array}$ & non déterminé & $\begin{array}{l}7.5 \\
7.7 \\
7.0 \\
6.7 \\
5.5\end{array}$ \\
\hline $\mathrm{C} 10$ & $\begin{array}{r}* 5 \mathrm{~h} \\
8 \mathrm{~h} \\
12 \mathrm{~h} \\
18 \mathrm{~h} \\
24 \mathrm{~h}\end{array}$ & $\begin{array}{l}5.0 \\
4.5 \\
4.45 \\
4.45 \\
4.45\end{array}$ & $\begin{array}{l}21.9 \\
31,9 \\
36.1 \\
37.1 \\
38.8\end{array}$ & non déterminé & $\begin{array}{l}9.6 \\
8.9 \\
8.4 \\
7.8 \\
7.5\end{array}$ \\
\hline
\end{tabular}

* moment de la coagulation des cultures. 
TABLEAU 2. - Activité des souches en fonction du temps d'incubation des cultures

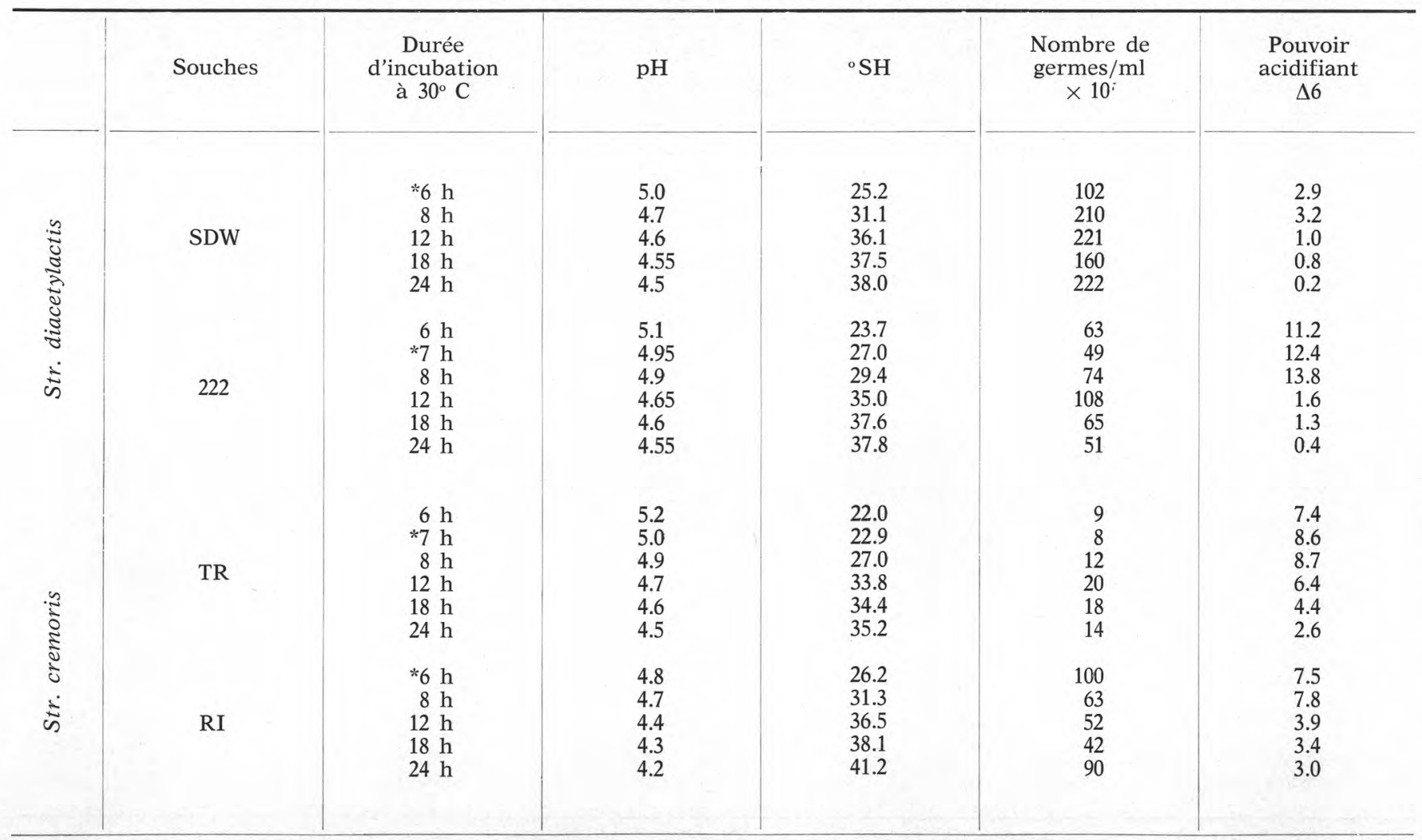


Au cours de l'incubation, le lait est constamment agité $(50 \mathrm{t} / \mathrm{mn})$ pour éviter la formation de zones à différent $\mathrm{pH}$.

Des prises d'échantillons aseptiques sont effectuées toutes les heures. On fait un dénombrement des cellules viables dans le milieu M.R.S. et on détermine le pouvoir acidifiant dans du lait pasteurisé, (selon les mêmes techniques que ci-dessus).

\section{RESULTATS}

1) Dans le tableau 1, sont présentés les résultats relatifs à l'activité des Str. Lactis en fonction du temps d'incubation.

Le nombre de germes ne donne pas d'indication valable sur l'évolution de l'activité des cultures car il demeure relativement constant.

C'est certainement la technique même du dénombrement qui est la cause des variations de numération observées.

Par contre les valeurs du pouvoir acidifiant sont telles que l'activité des Str. Lactis se révèle maximale au moment de la coagulation des cultures, se maintient dans les $2 \mathrm{~h}$ qui suivent, puis devient inversement proportionnelle au temps d'incubation.

Dans le tableau 2, sont inscrits les résultats relatifs aux Str. diacetylactis et Str. cremoris.

Comme précédemment, le nombre de germes viables d'une culture n'est pas le reflet de sa potentialité, puisque les variations sont très faibles au cours du temps.

L'examen des valeurs $\Delta 6$ montrent clairement que les 4 souches ont leur maximum de capacité fermentative dès la coagulation et que cette activité se maintient dans les $2 \mathrm{~h}$ suivantes. Une incubation plus longue a un effet néfaste sur la vitesse d'acidification des cultures.

Les résultats relatifs aux Str. thermophilus sont reproduits dans le tableau 3.

Comme précédemment, la population microbienne demeure constante quelle que soit la durée de l'incubation. Par contre le pouvoir acidifiant $\Delta 3$ met en évidence que l'activité est maximale au moment de la coagulation et qu'elle décroît plus ou moins brusquement selon les souches; le Str. thermophilus S19 devient presque inactif après $8 \mathrm{~h}$ d'incubation alors que les Str. thermophilus 24 et A.T.C.C. no 19987 sont moins endommagés par une acidité élevée.

Les résultats concernant les L. lactis A et A.T.C.C. $\mathrm{n}^{\circ} 15808$ et le L. helveticus $\mathrm{H}_{2}$ apparaissent dans le tableau 4 . 
TABLEAU 3. - Activité des Str. thermophilus en fonction du temps d'incubation des cultures

\begin{tabular}{|c|c|c|c|c|c|}
\hline Souches & $\begin{array}{c}\text { Durée } \\
\text { d'incubation } \\
\text { à } 40^{\circ} \mathrm{C}\end{array}$ & $\mathrm{pH}$ & ${ }^{\circ} \mathrm{SH}$ & $\begin{array}{c}\text { Nombre de } \\
\text { germes/ml } \\
\times 10^{7}\end{array}$ & $\begin{array}{c}\text { Pouvoir } \\
\text { acidifiant } \\
\Delta 3\end{array}$ \\
\hline 19987 A.T.C.C. & $\begin{array}{r}2 \mathrm{~h} \\
* 3 \mathrm{~h} \\
8 \mathrm{~h} \\
12 \mathrm{~h} \\
18 \mathrm{~h} \\
24 \mathrm{~h}\end{array}$ & $\begin{array}{l}5.4 \\
5.1 \\
4.6 \\
4.4 \\
4.3 \\
4.2\end{array}$ & $\begin{array}{l}16.0 \\
20.2 \\
32.0 \\
35.3 \\
38.3 \\
40.8\end{array}$ & $\begin{array}{l}16 \\
22 \\
20 \\
38 \\
26 \\
21\end{array}$ & $\begin{array}{l}6.2 \\
7.6 \\
5.8 \\
5.3 \\
5.1 \\
3.9\end{array}$ \\
\hline $\mathrm{S} 19$ & $\begin{array}{l}2 \mathrm{~h} \\
* 2 \mathrm{~h} 30 \\
8 \mathrm{~h} \\
12 \mathrm{~h} \\
18 \mathrm{~h} \\
24 \mathrm{~h}\end{array}$ & $\begin{array}{l}5.2 \\
4.9 \\
4.4 \\
4.1 \\
4.0 \\
3.9\end{array}$ & $\begin{array}{l}16.9 \\
23.2 \\
35.6 \\
44.8 \\
47.2 \\
47.5\end{array}$ & $\begin{array}{l}58 \\
52 \\
36 \\
25 \\
36\end{array}$ & $\begin{array}{l}6.2 \\
6.4 \\
1.6 \\
1.5 \\
1.3 \\
0.7\end{array}$ \\
\hline 24 & $\begin{array}{r}2 \mathrm{~h} \\
* 2 \mathrm{~h} 30 \\
8 \mathrm{~h} \\
12 \mathrm{~h} \\
18 \mathrm{~h} \\
24 \mathrm{~h}\end{array}$ & $\begin{array}{l}5.4 \\
4.1 \\
4.4 \\
4.1 \\
3.9 \\
3.9\end{array}$ & $\begin{array}{l}16.0 \\
22.5 \\
35.7 \\
43.5 \\
47.5 \\
48.5\end{array}$ & $\begin{array}{l}20 \\
37 \\
28 \\
22 \\
21\end{array}$ & $\begin{array}{l}5.3 \\
5.5 \\
5.1 \\
4.8 \\
4.3 \\
3.5\end{array}$ \\
\hline
\end{tabular}


TABLEAU 4. - Activité des Lactobacillus en fonction du temps d'incubation des cultures

\begin{tabular}{|c|c|c|c|c|c|c|}
\hline & Souches & $\begin{array}{c}\text { Durée } \\
\text { d'incubation en h } \\
\text { à } 40^{\circ} \mathrm{C}\end{array}$ & $\mathrm{pH}$ & ${ }^{\circ} \mathrm{SH}$ & $\begin{array}{l}\text { Nombre de } \\
\text { germes/ml } \\
\quad \times 10^{7}\end{array}$ & $\begin{array}{c}\text { Pouvoir } \\
\text { acidifiant } \\
\quad \Delta 6\end{array}$ \\
\hline 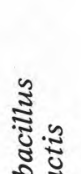 & A & $\begin{array}{r}* 5 \mathrm{~h} \\
8 \mathrm{~h} \\
12 \mathrm{~h} \\
18 \mathrm{~h} \\
24 \mathrm{~h}\end{array}$ & $\begin{array}{l}4.7 \\
4.5 \\
4.4 \\
4.2 \\
4.0\end{array}$ & $\begin{array}{l}25.5 \\
32.2 \\
38.3 \\
43.1 \\
53.5\end{array}$ & $\begin{array}{l}15 \\
16 \\
15 \\
12 \\
16\end{array}$ & $\begin{array}{l}14.1 \\
15.7 \\
18.4 \\
15.1 \\
12.7\end{array}$ \\
\hline $\begin{array}{l}\mathbb{E}^{2} \\
\text { J }\end{array}$ & 15808 A.T.C.C. & $\begin{aligned} 5 \mathrm{~h} \\
* 5 \mathrm{~h} \quad 30 \\
8 \mathrm{~h} \\
12 \mathrm{~h} \\
18 \mathrm{~h} \\
24 \mathrm{~h}\end{aligned}$ & $\begin{array}{l}5.1 \\
4.8 \\
4.5 \\
3.9 \\
3.8 \\
3.7\end{array}$ & $\begin{array}{l}17.4 \\
22.4 \\
36.1 \\
50.7 \\
62.8 \\
67.0\end{array}$ & $\begin{array}{r}3 \\
11 \\
24 \\
23 \\
23 \\
8\end{array}$ & $\begin{array}{r}6.8 \\
7.0 \\
10.6 \\
9.6 \\
8.9 \\
3.4\end{array}$ \\
\hline 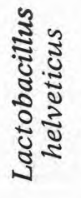 & $\mathrm{H} 2$ & $\begin{array}{r}5 \mathrm{~h} \\
* 6 \mathrm{~h} \\
8 \mathrm{~h} \\
12 \mathrm{~h} \\
18 \mathrm{~h} \\
24 \mathrm{~h}\end{array}$ & $\begin{array}{l}5.0 \\
4.7 \\
4.1 \\
3.7 \\
3.6 \\
3.5\end{array}$ & $\begin{array}{r}18.5 \\
27.1 \\
50.5 \\
75.6 \\
87.2 \\
102.3\end{array}$ & $\begin{array}{r}8 \\
22 \\
53 \\
64 \\
52 \\
69\end{array}$ & $\begin{array}{l}4.1 \\
6.4 \\
9.4 \\
8.1 \\
7.9 \\
4.3\end{array}$ \\
\hline
\end{tabular}


TABLEAU 5. - Evolution de la croissance des souches lactiques en culture à $\mathrm{pH}$ constant 6.5

\begin{tabular}{|c|c|c|c|c|c|c|}
\hline \multirow[b]{2}{*}{$\begin{array}{c}\text { Durée } \\
\text { d'incubation } \\
\text { en } \mathrm{h}\end{array}$} & \multicolumn{2}{|c|}{$\begin{array}{l}\text { Str. lactis } \\
\quad 272\end{array}$} & \multicolumn{2}{|c|}{$\begin{array}{l}\text { Str. thermophilus } \\
\text { L12 }\end{array}$} & \multicolumn{2}{|c|}{$\begin{array}{c}\text { Lb lactis } \\
\mathrm{A}\end{array}$} \\
\hline & $\begin{array}{l}\text { Nombre de } \\
\text { germes } / \mathrm{ml} \\
\quad \times 10^{8}\end{array}$ & $\begin{array}{c}\text { Pouvoir } \\
\text { acidifiant } \\
\Delta 6\end{array}$ & $\begin{array}{l}\text { Nombre de } \\
\text { germes/ml } \\
\quad \times 10^{7}\end{array}$ & $\begin{array}{l}\text { P.A. } \\
\Delta 3\end{array}$ & $\begin{array}{l}\text { Nombre de } \\
\text { germes/ml } \\
\quad \times 10^{8}\end{array}$ & $\begin{array}{l}\text { P.A. } \\
\Delta 6\end{array}$ \\
\hline $\begin{array}{r}0 \\
1 \\
2 \\
3 \\
4 \\
5 \\
6 \\
7 \\
8 \\
9 \\
10 \\
11\end{array}$ & $\begin{array}{l}19 \\
21 \\
22 \\
39 \\
60 \\
57 \\
52 \\
71 \\
81 \\
80\end{array}$ & $\begin{array}{l}4.4 \\
5.3 \\
5.9 \\
7.4 \\
8.2 \\
8.8 \\
9.8 \\
9.8 \\
9.6 \\
9.4\end{array}$ & $\begin{array}{c}4.4 \\
25 \\
28 \\
46 \\
105 \\
107 \\
75 \\
75 \\
82\end{array}$ & $\begin{array}{r}10.2 \\
11.8 \\
12.6 \\
11.3 \\
10.8 \\
10.6 \\
8.7\end{array}$ & $\begin{array}{r}2 \\
3 \\
23 \\
70 \\
71 \\
64 \\
64 \\
41 \\
33\end{array}$ & $\begin{array}{r}7.6 \\
8.1 \\
13.0 \\
14.5 \\
15.3 \\
14.0 \\
13.5 \\
13.1 \\
10.3\end{array}$ \\
\hline
\end{tabular}


A partir de la coagulation des cultures, le nombre de germes reste pratiquement constant ; les fluctuations sont normales et peuvent être considérées comme techniques.

La corrélation existant entre le pouvoir acidifiant et la durée d'incubation pour les Lactobacillus diffère un peu de celle observée avec les autres souches lactiques, le maximum d'activité ne se situe pas au moment de la coagulation mais dans les $2 \mathrm{~h}$ ou les $4 \mathrm{~h}$ qui suivent.

\section{2) Croissance des souches dans du lait maintenu à pH constant}

Les résultats, présentés dans le tableau 5 , sont assez semblables à ceux obtenus plus haut; le nombre de germes ne s'est pas accru dans de fortes proportions. La différence réside dans le fait que l'activité maximum, obtenue après un temps d'incubation correspondant au moment de la coagulation de la culture en dehors de toute neutralisation, se maintient davantage. Ceci est surtout vérifié pour les Str. lactis et Str. thermophilus.

\section{DISCUSSION}

De toutes les méthodes expérimentées $\mathrm{pH},{ }^{\circ} \mathrm{SH}$, nombre de germes et pouvoir acidifiant, c'est ce dernier test qui s'est révélé le plus valable pour apprécier l'activité des cultures.

Différents travaux $[1,5,7,8]$ sur la production dans des milieux plus ou moins définis de cultures concentrées, concentrées-congelées, avec ou sans neutralisation, ont mis en évidence que l'activité optimum était déjà obtenue après 6 à $8 \mathrm{~h}$ d'incubation pour les souches mésophiles (Str. lactis). Ces chercheurs ont également comparé l'activité des souches ainsi préparées avec des levains traditionnels dont l'acidification n'est arrêtée qu'après 18 à 24 h d'incubation.

L'étude critique des travaux mentionnés ci-dessus et l'examen de nos résultats montrent que la méthode de préparation des levains telle qu'elle est faite traditionnellement ne permet pas d'obtenir des cultures à activité élevée car le temps d'incubation est trop long.

Il nous semble donc plus justifié d'arrêter les cultures au début de leur coagulation.

Les avantages de cette méthode sont multiples : l'optimum de pouvoir acidifiant est acquis à ce moment par presque toutes les souches :

- il devient inutile de prélever des échantillons,

- les risques d'infection massive par les bactériophages sont diminués car on n'ouvre pas les cuves de fermentation et que les conditions favorables au développement des bactériophages ne sont réalisées que pendant un temps réduit, 
- les cultures peuvent être préparées avec succès dans la journée de travail. En inoculant les levains le matin, on peut contrôler le moment de leur coagulation et stopper aussitôt leur acidification,

- les cultures de laboratoire et les levains préparés de cette manière sont beaucoup plus actifs que ceux obtenus selon la méthode traditionnelle et on peut évaluer leur activité en fonction du temps qu'ils mettent à coaguler le lait.

Nos expériences sur la préparation de cultures maintenues à $\mathrm{pH}$ constant dans du lait n'ont pas confirmé les essais réalisés par d'autres auteurs dans des milieux plus ou moins définis, en ce qui concerne le nombre de germes.

On peut cependant noter une amélioration du pouvoir acidifiant qui prend une valeur maximale au moment de la coagulation normale des cultures et qui se maintient un peu plus longtemps à un niveau élevé.

Mais cela ne justifie pas l'achat d'un équipement coûteux indispensable pour pouvoir neutraliser les cultures en continu.

\section{R é s u m é}

On a étudié l'activité de 14 souches de ferments lactiques cultivés dans du lait en fonction du temps d'incubation.

Il apparaît que presque toutes les souches ont déjà atteint leur maximum d'activité dès la coagulation du milieu de culture.

La prolongation de l'incubation a un effet néfaste sur l'activité des cultures bien que le nombre de germes demeure constant ou s'accroisse.

\section{S u m m a r y}

The activity of fourteen lactic acid bacteria cultivated in milk were studied according to the incubation period.

The results obtained show that the maximum activity of nearly all the strains is reached when coagulation occurs. Prolongation of incubation has a negative effect on the culture activity although microorganism numbers remain stable or increase. 


\section{Bibliographie}

[1] Bergere (J. L.) et Hermier (J.) (1968). - Production massive de cellules de streptocoques lactiques. II. Croissance de «Streptococcus lactis » dans un milieu à $\mathrm{pH}$ constant. Le Lait, 48, 13-30.

[2] Botrazzi (V.). - Microbiology of Natural Starter used in Cheese manufacture (1966). XVII int. Dairy cong., D2, 509.

[3] Bristol (D. C.) and Martin (J. H.) (1970). - Non-coagulated, exponentialphase cultures, and pre-acidified skimmilk for decreasing the setting-time for manufacturing Cottage Cheese. J. Dairy Sci., 53, 10, 1381-1385.

[4] Hempenius (W. L.), Liska (B. J.) and Harrington (R. B.) (1965). - Consumer preferences for flavor in creamed cottage cheese. J. Dairy Sci., 48, 870.

[5] Keogh (B.) (1970). - Survival and activity of frozen startres cultures for cheese manufacture. Applied Microbiology, 19, 928-931.

[6] Man DE (J. C.) Rogosa (M.) Sharpe (E. A.) (1960). - Medium for the cultivation of Lactobacilli. J. Appl. Bacteriol., 23, 130.

[7] Peebles (M. M.), Gilliland (S. E.) and Speck (M. L.) (1969). - Preparation of concentrated Lactic Streptococcus Starters. Applied Microbiology, 17, 805-810.

[8] Rousseaux (P.), Vassal (L.), Valles (E.), Auclair (J.) et Mocouot (G.) (1968). Utilisation en fromagerie de gruyère de suspensions concentrées et congelées de bactéries lactiques thermophiles. Le Lait, 48, 241-254.

[9] Sozzi (T.). - Nuova tecnica per la preparazione dei latto innesti con ceppi di Streptococcus thermophilus. En préparation.

[10] Vassal (L.) et Mocouot (G.) (1967). - Fermentation lactique accélérée en fromagerie grâce à l'emploi d'un nombre élevé de bactéries. La technique laitière, 541, 913. 